\title{
Comparison of Caveolin-1 and PSA in Prostate Adenocarcinoma
}

\author{
Özkan Onuk¹ (D), Barış Nuhoğlu (D), Arif Özkan² (D), Tuncay Taş3 (D), Nusret Can Çilesiz² (D), Aydın İsmet Hazar² (D), \\ Mustafa Bahadır Can Balcı² (1) \\ 'Department of Urology, Yeni Yüzyıl University School of Medicine, İstanbul, Turkey \\ 2Department of Urology, University of Health Sciences Gaziosmanpaşa Taksim Training and Research Hospital, İstanbul, Turkey \\ ${ }^{3}$ Department of Urology, Esenyurt University İstanbul Cerrahi Hospital, İstanbul, Turkey
}

Cite this article as: Onuk Ö, Nuhoğlu B, Özkan A, Taş T, Çilesiz NC, Hazar Ai, et al. Comparison of Caveolin-1 and PSA in Prostate Adenocarcinoma. JAREM 2019; 9(3): 121-4.

\begin{abstract}
Objective: The aim of the present study was to evaluate caveolin-1 (CAV-1) levels as a possible alternative for the prostate specific antigen in the diagnosis of patients with prostate adenocarcinoma (PCa).

Methods: The study was conducted with 33 cases (mean age 67.2 (45-90) years) and 16 control patients (mean age 56.68 (48-77) years). Blood sample solution results of both the groups were read twice, and the average optical density of the zero standard was subtracted from the solution results' average.

Results: The average levels of prostate-specific antigen (PSA) were $1.1( \pm 0.64)$ for the control group and 12.3 ( \pm 8.7$)$ for patients with adenocarcinoma. The average levels of CAV-1 were $336( \pm 41.1)$ in the control group and $476( \pm 66.9)$ in patients with adenocarcinoma. PCa was detected in 33 patients, 27 of whom underwent prostatectomy, and the remaining 6 began hormonotherapy. Of these 33 patients, 2 had a Gleason score of 4, 16 had a Gleason score of 6, 10 had a Gleason score of 7, 3 had a Gleason score of 8, and 2 had a Gleason score of 9. Patients with PCa had higher PSA and CAV-1 than the control group $(p<0.05)$. CAV-1 (correlation parameter: 0.43) and PSA (correlation parameter: 0.48) were observed to increase with age $(p<0.05)$. A positive linear correlation was observed between PSA and CAV- 1 in all of the cases, but this relationship was not significant for cases with PCa $(p>0.05)$.

Conclusion: The level of CAV-1 was found to be higher in patients with PCa. CAV-1 can be used as an alternative for PSA, but it is not superior to PSA with respect to diagnosis, cost, and testing difficulty. In spite of the challenges its examination presents, CAV-1 is a protein, which should be tested in areas, such as early diagnosis, active surveillance, hormone refractory PCa, and radical prostatectomy.

Keywords: Caveolin, prostate carcinoma, PSA, prostate-specific antigen
\end{abstract}

\section{INTRODUCTION}

Prostate cancer is the most frequently observed neoplasia and the second most common reason for cancer-related deaths in men (1, 2). Approximately, one out of five men is diagnosed with prostate cancer. It is the fourth leading cancer in the world, and the incidence and mortality rates differ in each country (3). Beginning with the first half of the 1990s, new screening tests and developments in treatment caused dramatic changes in the phase of diagnosis and mortality. PSA belongs to the serine proteases multigene family localized on the kallikrein gene family locus on chromosome 19, identified in 1986 (4). PSA is currently used as a standard screening method, but the changes in PSA levels are insufficient for the diagnosis of prostate adenocarcinoma (PCa), resulting in a significant number of unnecessary biopsies. Accordingly, there is a search for potential alternative markers for the diagnosis of $\mathrm{PCa}$, one of which is caveolin-1 (CAV-1), a glycoprotein.

The purpose of the present study was to compare the CAV-1 levels of patients diagnosed with prostate cancer to their PSA results in order to evaluate if CAV-1 promises to be an alternative marker for PSA.

\section{Caveolin-1}

CAV-1 is a protein coded with the CAV1 gene in humans. This gene is a candidate repressor and a negative regulator of the Ras-p42/44 MAP cascade. CAV-1 and CAV-2 are located nearby on chromosome 7, and they express the proteins that form a stable hetero-oligomeric complex. 
Caveolae, which are a special type of lipid raft, are small (50-100 $\mathrm{nm}$ ) invaginations of the plasma membrane in many vertebrate cell types, especially in endothelial cells and adipocytes. Formation and maintenance of caveolae is primarily due to the protein caveolin, a $21 \mathrm{kDa}$ protein. There are three homologous genes of caveolin expressed in mammalian cells: CAV-1, CAV-2, and CAV-3. The normal secretion of the caveola is through highly differentiated epithelium cells, endothelium, heart muscle cells, adipocyte, and osteoblasts. Caveola contains highly concentrated signal molecule, G protein, tyrosine kinase receptors, and endothelial nitric oxide synthesis. These molecules interact with the caveolin protein containing 20 amino acids of CAV-1 called CAV-1 frame area (CAV-1 scaffolding domain, CSD). With the aid of the CSD-mediated activities, mobile sections of the caveola organize the signalization between the intracellular organelles and between the inside and the surface of the cell. A study conducted with mouse and human cells has reported that with respect to malignity development, CAV-1 plays a complicated role on the type of the cell, growth factor, and cell adhesion (5). Under certain conditions, CAV-1 can repress tumor formation (6). CAV-1 was also shown to be related to multiple mechanisms and to play a role on the progression of the malignity (7).

Patients with metastatic prostate cancers have higher intracellular CAV-1 expression levels than the normal population (8). Various studies have also shown that it plays an important role in hepatoma, leukemia, nose and pharynx carcinoma, oral cancers, breast cancer, and bladder or prostate cancer. CAV-1 rs3807987/ rs7804372 genotype is thought to be responsible for upper urethral tumors (9).

In the reported cell series of fatal prostate cancers, biologically, in vitro active CAV-1 protein is secreted, which is effective with respect to cellular vitality and clonal growth in prostate cancer $(10,11)$. Secreted CAV-1 was observed to display an anti-apoptotic quality in cancer formation. This quality could also be found inside the CAV1 cells $(10,12)$. In addition, CAV-1-mediated autocrine activities are displayed. A recent study has reported that cancer cells absorb this recombinant CAV-1 protein. Endothelial cells increase the angiogenic efficiency of the recombinant CAV-1 protein both in vivo and in vitro and mediate nitric oxide synthesis signalization in vivo (13).

Patients with cancer relapse following radical prostatectomy were reported to display high levels of serum CAV-1 (14).

New biomarkers, such as CAV-1, can be a strong indicator of the clinical result for various aggressive cancer types in humans (14).

\section{METHODS}

The study was conducted with 49 patients (33 in the experimental group and 16 in the control group). Oral informed consent was obtained from all the participants. The local ethics board approved the study. A total of 33 patients whose age ranged from 45 to 90 years, had no other malignancy in a different organ, had recently received a diagnosis of prostate adenocarcinoma, had received no prior treatment, and were planned to undergo either radical prostatectomy, radiotherapy, chemotherapy, or hormone therapy were included in the study as the experimental group. A limited number of patients who met the inclusion criteria but had a PSA level $>50$ were excluded from the study with statistical concerns. Blood samples were collected from both groups.

\section{Sera}

Blood samples were left to clot for 30 min before using a serum separator tube to centrifuge the samples for $15 \mathrm{~min}$ at a 1000gram cycle. The resulting serum was immediately analyzed. We divided an equal amount of samples to heparin, citrate, or EDTA tubes and kept them at $-20^{\circ} \mathrm{C}$. We refrained from repeating the congealment-defrosting procedure. Before usage, reactives and samples were heated at room temperature of ${ }^{\circ} \mathrm{C}$ Samples, both standard and control solutions, were analyzed twice.

\section{Range of Analysis}

Standard curve concentrations for ELISA tests were $2000 \mathrm{pg} / \mathrm{mL}$, $1000 \mathrm{pg} / \mathrm{mL}, 500 \mathrm{pg} / \mathrm{mL}, 250 \mathrm{pg} / \mathrm{mL}, 125 \mathrm{pg} / \mathrm{mL}, 62.5 \mathrm{pg} / \mathrm{mL}$, and $31.2 \mathrm{pg} / \mathrm{mL}$. This analysis recognized recombinant and natural human CAV-1. No significant cross-reactivity or interaction was observed. For CAV-1, a minimal detectable dose is typically $<7.8$ $\mathrm{pg} / \mathrm{mL}$. The sensitivity or lowest level of determination for this analysis is defined as the lowest protein concentration that can be distinguished from zero.

Each standard, control, and sample solution was read twice, and average measurements were obtained. Thereafter, the zero standard's average optical density was subtracted from this average measurement. Using a computer software capable of forming a four parameter logistic curve, we cleaned out the data to form a standard curve. The most compatible axis was determined by regression analysis.

The present study used a human caveolin-1 ELISA kit (microplate 96 test research kit; Cusabio Biotech Co., Ltd., China).

\section{RESULTS}

The present study was conducted in Taksim Training and Research Hospital Urology Clinic with 33 experimental group patients with a mean age of 67.2 (45-90) years and 16 control group patients with a mean age of 56.68 (48-77) years. PCa was detected in all 33 patients, 27 of whom had prostatectomy, and the remaining 6 began hormonotherapy. Of these 33 patients, 2 had a Gleason score of 4, 16 had a Gleason score of 6, 10 had a Gleason score of 7, 3 had a Gleason score of 8, and 2 had a Gleason score of 9 . In 3 patients who received biopsy, adenocarcinoma was detected on all cores. One patient had an area suspicious for metastasis, 2 patients had bladder stone, and 1 patient had cystic lesion in the liver.

PSA and CAV-1 were found to be higher in cases with PCa than in the control group (see Table) $(p<0.05)$.

CAV-1 (correlation coefficient: 0.43) and PSA (correlation coefficient: 0.48) were observed to increase with age (see Figure 1) $(p<0.05)$.

A linear correlation was observed between PSA and CAV-1 on all cases included in the study $(p<0.05)$.

In the linear regression graph that includes patients whose PSA was $>10$, there is no significant linear relationship between CAV-1 and Gleason score. Average scores were compared statistically using t-test. Linear regression analyses and Pearson correlation coefficients were used to examine the relationship between the two groups. 


\section{DISCUSSION}

Prostate cancer is one of the major health problems for the contemporary male society. In Europe, approximately 2.6 million people are diagnosed with cancer annually, and prostate cancer makes up $11 \%$ of all male cancers $(15,16)$.

During diagnosis, patients are tested for PSA and digital rectal examination (RT). However, PSA tests do not provide definitive information for cancer diagnosis. Consequently, there is a need for a new diagnostic parameter. A study has documented that men with benign prostate hyperplasia have higher serum CAV1 levels than men with prostate cancer (17). In our study, blood samples of patients with prostate cancer had statistically high levels, but in blood from patients having cancer, CAV-1 had the lowest level at $357 \mathrm{pg} / \mathrm{mL}$, and the highest level was detected in the control group patients at $410 \mathrm{pg} / \mathrm{mL}$, respectively. Whether these patients with low PSA levels have cancer is open for debate. However, we know that PSA level is not a definitive diagnostic parameter. Even though we found a linear correlation between patients' PSA result and their CAV-1 levels, separate analyses of the control group and the cancer group did not provide similar result.

Raventós and colleagues have studied 280 patients and reported that based on the results of the prostate biopsies conducted according to the D'Amico criteria, cancer in one core or minimum tumor value of $0.45 \mathrm{~cm} 3$ provides guidance for deciding between radical surgery and active surveillance (18). In our study, the biopsy percentage of patients with prostate cancer did not have a

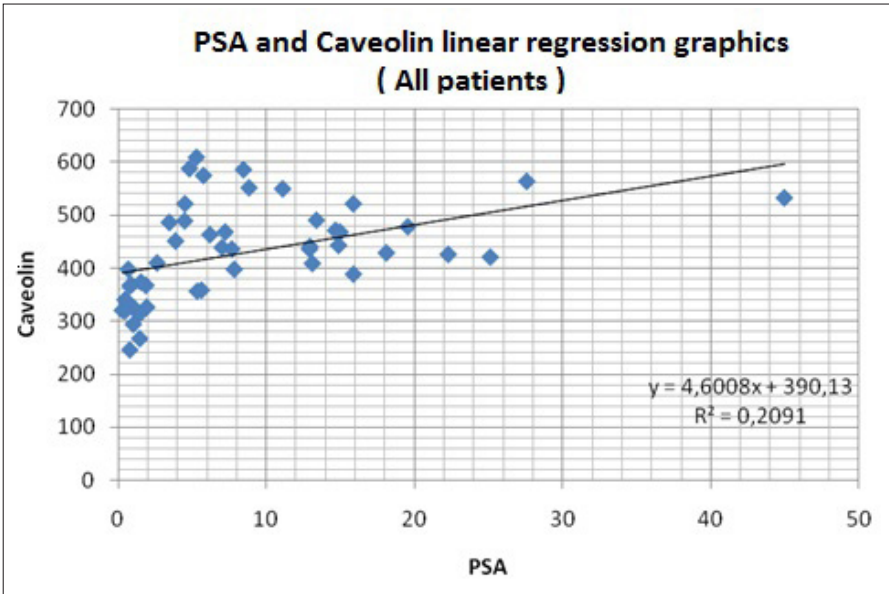

Figure 1. Correlation between PSA and caveolin

Table. Comparison of two groups (prostate cancer and control groups)

\begin{tabular}{l|c|c|c|} 
& PCa(+) & PCa(-) & P \\
\hline $\begin{array}{l}\text { Average } \\
\text { value } \\
\text { of caveolin }\end{array}$ & $476 \pm 66.9(357-608)$ & $336 \pm 44.1(247-410)$ & $<0.05$ \\
\hline $\begin{array}{l}\text { Average } \\
\text { age }\end{array}$ & $67.3 \pm 9.1(45-96)$ & $56.7 \pm 7.6(48-77)$ & $<0.05$ \\
\hline $\begin{array}{l}\text { Average } \\
\text { PSA }\end{array}$ & $12.3 \pm 8.7(3.47-45)$ & $1.1 \pm 0.64(0.34-2.64)$ & $<0.05$ \\
\hline
\end{tabular}

statistically significant relationship with CAV-1 levels. Neither did the linear regression graph of the PSA result of these patients provided significant results. Such changes in the CAV-1 and PSA levels serve as a guideline in our decisions about low-grade patients who would benefit from active surveillance.

Guang Yang and colleagues conducted a study in which they analyzed 189 radical prostatectomy specimens using the Cox regression model and reported that CAV-1 is an independent prognostic factor for indicating progression. CAV-1 levels were related to not only Gleason score, lymph node positivity, metastasis, and positive surgical margins but also the progression of prostate cancer (19)

In our study, on the other hand, there was no significant relationship between the Gleason score and CAV-1 levels.

Tahir et al. (20) studied 419 patients diagnosed with PCa and indicated that a combination of serum PSA $>10 \mathrm{ng} / \mathrm{mL}$, serum CAV-1, and biopsy Gleason score can predict recurrence. In our study, regression graph of patients with PSA scores $>10$ failed to provide a significant result. This suggests that our results do not support the findings of Tahir and colleagues.

CAV-1 loss in the prostate cancer stroma was shown to be related to recurrence, survival, and tumor progression (21).

In light of this information, even though CAV-1 levels were high in patients with prostate cancer, our results indicate that it is not related to the Gleason score, tumor volume, or PSA levels. Therefore, this information is not sufficient for deciding which patient should be considered under active surveillance. Thousands of patients worldwide undergo unnecessary biopsy due to high PSA, indicating high costs and loss of workforce. In our study, the control group patients had higher CAV-1 levels than patients with prostate cancer, and the question regarding which patients can be spared of prostate biopsy remained unanswered.

Since the CAV-1 ELISA kit is not routinely used, automatic equipments for evaluating the level of this marker are not developed. Measuring CAV-1 levels require human power. Since it is still on the research phase, it is used for company-supported research rather than that for diagnostic purposes. As a result, its testing cost per unit is 3-4 times higher than routinely used PSA.

\section{CONCLUSION}

The widespread use of blood testing for PSA resulted in an increase in the number of prostate biopsies for early diagnosis of prostate cancer. Out of four men who undergo prostate biopsy due to high PSA, only one has prostate cancer. Furthermore, considering some men have normal levels of serum PSA, tumor diagnosis can be late in patients with prostate cancer. There are currently genetic and molecular studies, such as the PCA3 gene tested on a urine sample that are expected to aid the diagnosis of prostate cancer (22). In conclusion, in spite of the testing difficulties and high costs related to this marker, CAV-1 research is promising. Therefore, CAV-1 tests should be further researched for the diagnosis and surveillance of prostate cancer.

Ethics Committee Approval: Ethics committee approval was received for this study from the Ethic Committee of Taksim Training and Research Hospital (TAEH EK /2010). 
Informed Consent: Verbal informed consent was obtained from the patients who participated in this study.

Peer-review: Externally peer-reviewed.

Author Contributions: Concept - Ö.O., M.B.C.B.; Design - Ö.O., M.B.C.B.; Supervision - Ö.O., A.I.H.; Resources - Ö.O., A.I.H.; Materials - T.T., A.Ö.; Data Collection and/or Processing - T.T., A.Ö.; Analysis and/or Interpretation - I.H., B.N.; Literature Search - Ö.O.,T.T.; Writing Manuscript - Ö.O.; Critical Review - B.N., M.B.C.B.

Conflict of Interest: The authors have no conflict of interest to declare.

Financial Disclosure: The authors declared that this study has received no financial support.

\section{REFERENCES}

1. Rosai J. (2004) Rosai and Ackerman's Surgical Pathology. (9. baskı) Chapter 18, Male Reproductive System. Elsevier Inc. 1361-411.

2. Epstein JI, Kumar V, Abbas AK, Fausto N. (2005). The Lower Urinary Tract and Male Genital System. (7. baskı) Chapter 21. Robbins and Cotran PathologicDisease. Philadelphia: Elsevier Saunders. 1023-58.

3. Walsh PC, Retik BA, Vaughan ED, Wein AJ. Campbell's urology. 9th ed. Philadelphia: Saunders Co., 2007: 3001-221.

4. Hernandez J, Thompson IM. prostate-specific antigen a review of the validation of the most commoly used cancer biomarker. Cancer 2004; 101: 894-904. [CrossRef]

5. Corn PG, Thompson TC. Identification of a novel prostate cancer biomarker, caveolin-1: Implications and potential clinical benefit. Cancer Manag Res 2010; 10: 111-22. [CrossRef]

6. Williams TM, Lisanti MP. Caveolin-1 in oncogenic transformation, cancer, and metastasis. Am J Physiol Cell Physiol 2005; 288: 494506. [CrossRef]

7. Cavallo-Medved D, Mai J, Dosescu J, Sameni M, Sloane BF. Caveolin-1 mediates the expression and localization of cathepsin $B$, pro-urokinase plasminogen activator and their cell-surface receptors in human colorectal carcinoma cells. J Cell Sci 2005; 118 : 1493-503 [CrossRef]

8. Yang G, Truong LD, Wheeler TM, Thompson TC. Caveolin-1 expression in clinically confined human prostate cancer: a novel prognostic marker. Cancer Res 1999; 59: 5719-23.

9. Chang WS, Lin SS, Li FJ, Tsai CW, Li LY, Lien CS, et al. Significant association of caveolin-1 (CAV1) genotypes with upper urothelial tract cancer. Anticancer Res 2013; 33: 4907-12.

10. Tahir SA, Yang G, Ebara S, Timme TL, Satoh T, Li L, et al. Secreted caveolin-1 stimulates cell survival/clonal growth and contributes to metastasis in androgen-insensitive prostate cancer. Cancer Res 2001; 61: 3882-5.

11. Bartz R, Zhou J, Hsieh JT, Ying Y, Li W, Liu P. Caveolin-1 secreting LNCaP cells induce tumor growth of caveolin-1 negative LNCaP cells in vivo. Int J Cancer 2008; 122: 520-5. [CrossRef]

12. Li L, Ren CH, Tahir SA, Ren C, Thompson TC. Caveolin-1 maintains activated Akt in prostate cancer cells through scaffolding domain binding site interactions with and inhibition of serine/threonine protein phosphatases PP1 and PP2A. Mol Cell Biol 2003; 23: 9389 404. [CrossRef]

13. Tahir SA, Yang G, Goltsov AA, Watanabe M, Tabata K, Addai J, et al. Tumor cell-secreted caveolin-1 has proangiogenic activities in prostate cancer. Cancer Res 2008; 68: 731-9. [CrossRef]

14. Tahir SA, Frolov A, Hayes TG, Mims MP, Miles BJ, Lerner SP, et al. Preoperative serum caveolin-1 as a prognostic marker for recurrence in a radical prostatectomy cohort. Clin Cancer Res 2006; 12 : 4872-5. [CrossRef]

15. Martinez-Outschoorn UE, Lisanti MP, Sotgia F. Catabolic cancerassociated fibroblasts transfer energy and biomass to anabolic cancer cells, fueling tumor growth. Semin Cancer Biol 2014; 25: 47-60. [CrossRef]

16. Bray F, Sankila R, Ferlay J, Parkin DM.Estimates of cancer incidence and mortality in Europe in 1995. Eur J Cancer 2002; 38: 99-166. [CrossRef]

17. Tahir SA, Ren C, Timme TL, Gdor Y, Hoogeveen R, Morrisett JD, et al. Development of an immunoassay for serum caveolin-1: a novel biomarker for prostate cancer. Clin Cancer Res 2003; 9: 3653-9.

18. Raventós CX, Orsola A, de Torres I, Cecchini L, Trilla E, Planas J, et al. Preoperative Prediction of Pathologically Insignificant Prostate Cancer in Radical Prostatectomy Specimens: The Role of Prostate Volume and the Number of Positive Cores. Urol Int 2010; 84: 1538. [CrossRef]

19. Yang G, Truong LD, Wheeler TM, Thompson TC. Caveolin-1 Expression in Clinically Confined Human Prostate Cancer: A Novel Prognostic Marker1. Cancer Research 1999; 59: 5719-23.

20. Tahir SA, Frolov A, Hayes TG, Mims MP, Miles BJ, Lerner SP, et al. Preoperative Serum Caveolin-1 as a Prognostic Marker for Recurrence in a Radical Prostatectomy Cohort. Clin Cancer Res 2006; DOI: 10.1158/1078-0432.CCR-06-0417. [CrossRef]

21. Ayala G, Morello M, Frolov A, You S, Li R, Rosati F, et al. Loss of caveolin-1 in prostate cancer stroma correlates with reduced relapsefree survival and is functionally relevant to tumour progression. J Pathol 2013; 231: 77-87. [CrossRef]

22. Luo B, Wang AL. An update of the markers for prostate cancer. Zhonghua Nan Ke Xue 2010; 16: 531-5. 